\title{
FRATERNIDADE E DIREITO EM TEMPOS DE PANDEMIA
}

\author{
Carlos Augusto Alcântara Machado ${ }^{1}$
}

DOI: https://doi.org/10.47306/978-65-88213-03-2.179-191

Sumário: 1 Considerações introdutórias; 2 Um breve histórico da evolução dos direitos humanos: da liberdade à fraternidade; 3 Propostas conceituais para a fraternidade: a contribuição de Amaya e Barzotto; 4 Fraternidade como categoria jurídica: uma proposta para o momento em que vivemos; 5 Conclusão. Referências.

\section{Considerações introdutórias}

A humanidade vive tempos difíceis. Perguntas várias se apresentam; questionamentos diversos exsurgem para as ciências em geral. Não se ignora que o Direito também deverá dar uma resposta, pois, como aduz Néfi Cordeiro (2020a), “a pandemia da Covid-19 a todos surpreendeu pela gravidade da doença e pela necessária mudança de hábitos”, conduzindo, em face do isolamento social, imperiosas mudanças, nas pessoas, mas também no Direito. O mundo não é mais o mesmo e as respostas não mais poderão ser análogas às até então praticadas, diante dos conflitos sociais notoriamente potencializados.

De fato. O desastre humanitário da pandemia da Covid-19 expôs as fragilidades humanas e equiparou, em certo sentido, a todos, uma vez que o vírus não poupa ninguém, nem se manifesta atentando a condições econômicas, sociais, de gênero, raça, ou a qualquer outro elemento discriminatório. Todos, todos indeterminadamente, serão potenciais infectados e passíveis dos efeitos da doença, com risco efetivo de letalidade. Daí a constatação de que o Novo Corona Vírus mesmo se considerado um vírus "democrático", evidencia fragilidades da própria democracia (ABRAHÃO, 2020). Outros, diversamente, se opõem à qualificação, da primeira parte da sentença, por reconhecerem que não poderá haver "vírus democrático" em sociedades desiguais (SEDUFSM, 2020). Isto porque, como referem alguns com destacada sensibilidade, "o contágio é democrático; prevenção, não" (LIMA, 2020). Ou ainda, por justificáveis razões, "o vírus pode até ser democrático, mas a pandemia, não” (LIMA, 2020b).

Sem embargo da abordagem inicial passível de suscitar calorosos debates, não se pode deixar de aperceber que a humanidade, diante da emergência sanitária, depara-se com a sua própria natureza corpórea e, por conseguinte, falível, limitada.

A propósito da inexorável constatação, reverbera-se no presente estudo, significativa

\footnotetext{
${ }^{1}$ Doutor em Direito. Procurador de Justiça do Ministério Público do Estado de Sergipe. Professor Adjunto dos cursos de graduação e mestrado da Universidade Federal de Sergipe e do Mestrado em Direito Humanos da Universidade Tiradentes. E-mail: cmachado@infonet.com.br
} 
reflexão levada a efeito pelo filósofo e teólogo Jesús Morán (2020, p. 70), na sua coluna mensal ("Pensare l'unitá"), publicada na revista italiana Città Nuova. Com o título "Siamo (un) corpo", o autor inicia as suas considerações invocando a lições de Blaise Pascal e de Xavier Zubiri, nos seguintes termos:

Nell' imponente Preguiera per chiedere a Dio il buon suo della malattie, il genio
francese Blaise Pascal dice, in sintese, che l'uomo è le sue malattie. Anche il filosofo
spagnolo Xavier Zubiri si esprime in simille termine quando afferma che, a raggione
delle sue estrutture, 'l'uomo non può non avere malattie'. In questo tempo di pandemia
convienne riflettere seriamente sua questa costatazione.

Ao aduzir que "não haveria doença se o homem não fosse um ser essencialmente corpóreo", desenvolve o autor, seguidamente, a elucubração do ponto de vista teológico, partindo do referencial cristão: "o cristianismo oferece à consciência religiosa da humanidade a visão de um Deus que se transforma em um de nós", tornando-se homem. Analisa, assim, as consequências de um Deus que se torna homem, e, portanto, "encarna-se e recebe um corpo e se submete radicalmente a esta nova condição”. Particularmente em razão disso, alcança-se um novo significado para a doença e para a morte.

Mas prosseguir no percurso não é o objeto do artigo em desenvolvimento. A referência ao texto de Morán - "Somos (um) corpo" - serviu para destacar a nossa existência corpórea, e por conta disso, reconhecer que todos, todos indistintamente, apresentam-se como limitados e iguais em natureza e dignidade.

Buscar-se-á no presente estudo, recuperar, brevemente e num momento inicial, o histórico da evolução dos direitos humanos, suas fases, até alcançar o estágio de universalização, com especial ênfase para a fraternidade, desta feita compreendida numa perspectiva jurídica. Em seguida evidenciar-se-á, o seu respectivo papel, notadamente em tempos de pandemia. Numa subsequente etapa, a reflexão se valerá dos aportes conceituais sobre a fraternidade, a partir do magistério de Amalia Amaya e de Luís Fernando Barzotto, para ao final, numa terceira e conclusiva seção, apresentar as considerações finais.

\section{Um breve histórico da evolução dos direitos humanos: da liberdade à fraternidade}

Os Direitos Humanos, das origens à positiva universal, passaram por um amplo processo evolutivo.

Inspirado no magistério de Norberto Bobbio, Giuseppe Tosi, pedagógica e resumidamente, discorreu sobre as três fases que integram o denominado movimento histórico de afirmação dos direitos humanos na modernidade (TOSI, 2014, p. 253), assim se expressando: 


\begin{abstract}
A primeira fase se refere às teorias filosóficas jusnaturalistas dos séculos XVII e XVIII que proclamavam a igualdade e a liberdade naturais de todos os homens, mas que não possuíam valor de lei [a chamada fase universal, mas não positiva]; a segunda fase é a passagem do 'direito pensado para o direito realizado', ou seja, acolhimento das doutrinas jusnaturalistas no direito interno de alguns Estados a partir das revoluções burguesas e socialistas [a identificada como fase positiva, mas não universal]; a terceira e última fase inicia com a Declaração Universal dos Direitos Humanos de 1948 [reconhecida por fase universal e positiva].
\end{abstract}

De fato, Norberto Bobbio (2004, p. 28-29), o gênio italiano - jusfilósofo, legislador e pensador - identificou os estágios do citado processo evolutivo, apresentando como ponto de partida, o reconhecimento de declarações de direitos, inicialmente como teorias filosóficas (etapa inicial). Quando tais teorias filosóficas passaram a ser acolhidas pelo legislador, compondo textos positivos forjados mediante Declarações de Direitos, todas formalizadas em documentos eloquentes, a partir do último quartel do século XVIII, eis que surge a fase subsequente do histórico percurso. Nessa segunda etapa, no entanto, os consagrados direitos agora resultantes da "passagem da teoria à prática", como destaca o ilustrado autor -, perdem o caráter de universalidade, porquanto garantidos tão somente no específico âmbito de cada Estado singularmente considerado. Como registrou Bobbio (2004, p. 29), a propósito da segunda fase do anunciado iter, "a afirmação dos direitos do homem ganha em concreticidade, mas perde em universalidade".

É de se reconhecer que nos dois indigitados estágios, caracterizados, o primeiro, sob o viés do universalismo, e o segundo, limitado pela rígida moldura do direito positivo, restaram especialmente prestigiados os valores liberdade e igualdade e, a partir deles, o que se convencionou denominar de direitos naturais (primeira fase) e, posteriormente, direitos civis, políticos, culturais, econômicos e sociais (segunda fase).

A Declaração Universal dos Direitos Humanos, editada em 1948, apresentou-se como o marco temporal - assim aduziu Bobbio (2004, p. 29) -, da terceira e última etapa desse examinado processo histórico, quando a afirmação de direitos passou a ser, a um só tempo, universal e positiva, conjugando as características que destacavam, singular e respectivamente, como a primeira e a segunda fases.

O consenso jurídico global funcionou, desse modo, como o marco da etapa conclusiva da evolução dos direitos humanos fundamentais, em outra doutrina também identificada em três fases, de gerações ou dimensões, expressas em modelos de Estados diversos: liberal (liberdade), social (igualdade) e, por derradeiro, fraternal (fraternidade).

O solene compromisso planetário, aglutinando os três estágios antes referidos, foi identificado logo no art. $1^{\circ}$ da Declaração Universal, em significante dicção: “Todos os seres humanos nascem livres e iguais em dignidade e direitos. São dotados de razão e consciência e 
devem agir em relação uns aos outros com espírito de fraternidade" (sem o destaque no original).

Anos depois e materializando os ideais de liberdade e de igualdade, em forma de direitos, vieram a lume os conhecidos Pactos Internacionais de Direitos Humanos. Inicialmente, o Pacto Internacional sobre Direitos Civis e Políticos, adotado pela Assembleia-Geral da ONU, em 16.12.1966 (no Brasil, promulgado pelo Decreto $n^{\circ}$ 592, de 03 de julho de 1992) e, em seguida, o Pacto Internacional de Direitos Econômicos, Sociais e Culturais, aprovado pelas Nações Unidos, em 19.12.1966 (no Brasil, promulgado pelo Decreto ${ }^{\circ}$ 591, de 03 de julho de 1992).

Como é possível perceber, a humanidade avançou percorrendo gerações de direitos por vezes também referidas como dimensões de direitos - desde a pioneira menção nos idos de 1979, atribuída a Karel Vasak, quando vislumbrou no processo de desenvolvimento dos clássicos direitos de liberdade e de igualdade, uma nascente terceira geração, a dos direitos de fraternidade ou de solidariedade, descortinando, como reconhece Paulo Bonavides (2011, p. 569), "um novo pólo jurídico de alforria do homem".

Não se desconhece que outros autores identificaram, posteriormente, uma quarta e até uma quinta geração de direitos (BONAVIDES, 2011, p. 570-572 e p. 579-593). No entanto, para utilizar como referência simbólica o lema revolucionário francês, é de se delimitar a análise em três dimensões, identificando-as, inclusive, com a titularidade dos direitos declarados e protegidos, bem como ao objeto, como destaca Sérgio Resende de Barros $^{2}$, em sintéticos, mas esclarecedores textos. A primeira dimensão, que tem como titularidade, "o ser humano como indivíduo (singularidade)" e como objeto, "a defesa da liberdade individual" (liberté); a segunda, alcançando a titularidade do "ser humano em uma categoria ou parte social (parcialidade)" e como objeto "a promoção da igualdade social" (égalité) e, por fim, a terceira geração, apresentando-se a titularidade no "ser humano como gênero humano (generalidade)" e como objeto "a defesa da humanidade e a promoção da solidariedade humana" (fraternité).

Ultrapassados os estágios da "liberdade" e da "igualdade" e, como natural consequência, da sedimentação dos estudos envolvendo os direitos de liberdade e os direitos da igualdade, atingiu-se a fase em que a humanidade se encontra: a da fraternidade.

Os direitos de fraternidade (ou de solidariedade) foram inicialmente concebidos - é certo - no domínio do direito internacional, como, verbi gratia, o direito ao desenvolvimento,

2 Ver "Aulas" e "Artigos", na primeira, "Noções sobre Gerações de Direitos", disponível em http://www.srbarros.com.br/pt/nocoes-sobre-geracoes-de-direitos.cont e no segundo, "Três Gerações de Direitos", disponível em http://www.srbarros.com.br/pt/tres-geracoes-de-direitos.cont, Acessos em: 28 jun. 2020. 
o direito ao meio ambiente e o direito à paz. Após a proclamação inaugural, alguns Estados passaram a consagrá-los - ou, quando menos - programaticamente anunciá-los, na ordem interna mesmo, como ocorreu na República Federativa do Brasil, com a promulgação da Constituição de 1988.

No compromisso preambular, a Constituição de 1988 anunciou que o Estado brasileiro, juridicamente concebido, deveria perseguir a realização de uma sociedade fraterna, pluralista e sem preconceitos, fundada na harmonia social e comprometida na ordem interna e internacional, com a solução pacífica das controvérsias. Eis o inteiro teor do preâmbulo:

\begin{abstract}
Nós, representantes do povo brasileiro, reunidos em Assembléia Nacional Constituinte para instituir um Estado Democrático, destinado a assegurar o exercício dos direitos sociais e individuais, a liberdade, a segurança, o bem-estar, o desenvolvimento, a igualdade e a justiça como valores supremos de uma sociedade fraterna, pluralista e sem preconceitos, fundada na harmonia social e comprometida, na ordem interna e internacional, com a solução pacífica das controvérsias, promulgamos, sob a proteção de Deus, a seguinte CONSTITUIÇÃO DA REPÚBLICA FEDERATIVA DO BRASIL (sem o destaque e o grifo no original).
\end{abstract}

Em seguida, no art. $3^{\circ}$, logo no inciso inicial (I), o legislador constituinte indicou como objetivo fundamental da República Federativa do Brasil construir uma sociedade, além de livre e justa - objetivos tradicionalmente consagrados em textos constitucionais clássicos e contemporâneos - também solidária. Construir uma sociedade solidária, um dos seus objetivos supremos. Utilizou-se do vocábulo "solidária", que na verdade deve ser compreendida como "fraterna", como registrou Ayres Britto, em manifestação de voto, no exercício de nobre mister de excelso julgador, no Supremo Tribunal Federal, há quase duas décadas (2004), quando do julgamento da ADI 3.128-7/DF³.

Todavia, sem embargo da positivação jurídica no documento nacional de maior dignidade normativa, indaga-se: qual o alcance da fraternidade, compreendida como categoria jurídica (MACHADO, 2017a) ou como valor jurídico (MACHADO, 2017b) ou, ainda, mais especificamente, como princípio constitucional (FONSECA, 2019), numa perspectiva de aplicabilidade e eficácia? É possível avançar nessa compreensão? Como a sociedade deverá se comportar em vista da construção de uma "sociedade fraterna" ou para atingir uma "sociedade solidária”, particularmente em tempos de pandemia? Como o Direito poderá contribuir para fomentar condutas fraternas?

\footnotetext{
${ }^{3}$ Disponível em: http://redir.stf.jus.br/paginadorpub/paginador.jsp?docTP=AC\&docID=363314. Acesso em: 29 maio 2020 .
} 


\section{Propostas conceituais para a fraternidade: a contribuição de Amaya e Barzotto}

Mas o que se entende por práticas fraternas; por um agir pautado na fraternidade?

Como ponto central da reflexão proposta no presente artigo e objetivando alcançar as respostas às indagações formuladas, o estudo valer-se-á dos aportes doutrinários de Amalia Amaya e de Luís Fernando Barzotto, em específicos textos sobre o tema, notadamente os que buscam definir (ou quanto menos propor) uma moldura conceitual para a fraternidade.

Em primoroso artigo intitulado "La relevancia de la fraternidad" (2016, p. 21-38), a professora Amalia Amaya, vinculada ao Instituto de Investigações Filosóficas da Universidade Nacional Autônoma do México (UNAM), desenvolveu importante reflexão sobre a fraternidade, materializada em quatro etapas.

$\mathrm{Na}$ primeira etapa da sua reflexão, Amaya examinou as razões de o conceito da fraternidade ter sido historicamente esquecido ou, nas suas palavras, ocupar "um lugar marginal no debate político contemporâneo", permanecendo relegado no pensamento filosófico. Na segunda seção, a autora perquiriu algumas das aproximações filosóficas que, direta ou indiretamente, se ocuparam do conceito de fraternidade e, em seguida, realizou uma análise do conceito de fraternidade, diferenciando-o de outras concepções afins na teoria política.

Como abordagem derradeira, a autora trouxe uma série de questões que, ao seu juízo, deveriam ser consideradas no desenvolvimento teórico da fraternidade, desde que concebida como ideal político. As questões destacadas, pois, apresentar-se-iam, ao seu juízo, como notáveis desafios aptos a compor uma "agenda de investigação futura sobre esse conceito".

Obediente à sua proposta de reflexão, após ter percorrido as duas primeiras seções do itinerário pretendido, Amalia Amaya identificou três dimensões (2016, p. 29-32), explicitadas como condições constitutivas da fraternidade: a dimensão comunitária, a dimensão afetiva e a dimensão prática. Admitiu, no entanto, que as diversas dimensões permitiriam alcançar distintas interpretações e, consequentemente, resultar em concepções diversas da fraternidade.

Relativamente as dimensões da fraternidade, explicitou (2016, p. 31):

La dimensión comunitaria nos permite diferenciar el vínculo fraternal de otras relaciones sociales, e.g., relaciones de mercado o relaciones de servidumbre. Las disposiciones afectivas y prácticas características del vínculo fraternal son también constitutivas de dicho vínculo: si mi hermano de armas no se preocupa por mi seguridad ni está dispuesto a prestarme ayuda en la necesidad difícilmente se le puede llamar con propiedad hermano. La carencia de las actitudes afectivas y prácticas características de la fraternidad implica un debilitamiento del mismo vínculo fraternal.

Em síntese conclusiva, sobre as condições em destaque, Amalia Amaya (2016, p. 32), acrescentou: 
La fraternidad se realiza en una comunidad cuando se satisfacen tres condiciones: a) cada miembro reconoce a los otros miembros como iguales en virtud de un valor o rasgo compartido, b) los miembros de la comunidad están ligados por lazos afectivos, y c) tienen una disposición a ayudarse mutuamente.

Na parte final do estudo temático, tratando mais especificamente dos desafios que se apresentavam no aprofundamento reflexivo, a autora sinalizou, com absoluta propriedade, para a necessidade de ressignificação dos clássicos princípios integrantes do tríptico revolucionário francês - liberdade e igualdade - a partir do conceito de fraternidade.

Sobre o aspecto, aduz Amalia Amaya (2016, p. 33):

Parece necesario explorar la relación entre fraternidad y los conceptos de libertad y, especialmente, igualdad. Por un lado, un argumento a favor de la igualdad parte del reconocimiento de que la misma es indispensable pare realizar los ideales de la fraternidad. Por otro lado, parece que la igualdad es no una condición sino una consecuencia de la fraternidad, ya que una actitud fraternal favorece un reparto igualitario de recursos. En todo caso, parece plausible sostener de nuevo que el concepto de fraternidad conlleva una importante resignificación de las ideas de libertad e igualdad.

Arrematando o estudo, como considerações finais e conclusivas, a autora reconheceu que a fraternidade "requiere [...] que una comunidad estructure sus relaciones sociales de tal manera que sus miembros se reconozcan como iguales, estén ligados por lazos afectivos y dispuestos a cooperar y a ayudarse mutuamente" (AMAYA, 2016, p. 34).

Em concepção doutrinária similar, socorre-se, desta feita, ao magistério de Luís Fernando Barzotto (2018). Aprofundando o conceito de fraternidade, o Professor da Universidade Federal do Rio Grande do Sul alcançou conclusões que, em alguns aspectos, aproximam-se das obtidas por Amalia Amaya.

Partindo da constatação de que a fraternidade, conceitualmente, está ligada à ideia de dever, enquanto a liberdade e igualdade, comumente, encontram-se associadas a direitos, evidenciou o autor uma das razões por força da qual a fraternidade, dentre os princípios integrantes do clássico lema da modernidade (liberté, egalité, fraternité), tornou-se periférico (“membro fraco") em relação aos outros dois. E justificou (2018, p. 79):

Ligada à ideia de dever, a Fraternidade, em uma cultura que fomenta o individualismo e o autointeresse, teria que se tornar o membro fraco da tríade: na sociedade individualista moderna, os deveres, que vinculam as pessoas entre si, cedem diante dos direitos, que são exigidos, em geral, para si, e não para os outros.

Barzotto (2018, p. 81-82) busca encontrar um conceito para a fraternidade, associando-a a categoria do reconhecimento, pois, como desenvolve, "reconhecer o outro é 'vêlo como' um irmão", mesmo que não o seja, de fato. Para o autor, "o reconhecimento é uma atitude complexa, com três momentos, cada um deles dirigido a um dos aspectos da identidade do outro como irmão": reconhecimento como solidariedade; reconhecimento como respeito e 
reconhecimento como reciprocidade.

No primeiro momento do reconhecimento, inicialmente destacado como solidariedade, Barzotto sobreleva que reconhecer o outro, "é assumir a responsabilidade por ele", já que "o bem de cada um é o bem de todos", agregando um aspecto tipicamente comunitário de que "todos são responsáveis por todos" (2018, p. 82). Reconhecimento como solidariedade, portanto, como primeiro momento. Poder-se-ia, no ponto, associar com a dimensão comunitária suscitada na reflexão desenvolvida por $\mathrm{Amaya}^{4}$, e, num certo sentido, também com a dimensão prática ${ }^{5}$.

Em seguida, o autor incorpora ao reconhecimento a dimensão de respeito (reconhecimento como respeito), porquanto, além da solidariedade (responsabilidade com o outro), deve-se ter em relação ao outro, respeito na sua liberdade, "definida a partir três dimensões constitutivas: independência, escolha e autoria". A fraternidade, como sobressai (2018, p. 84), “exige respeito: não ocultar a liberdade do outro, mas afirmá-la. A atitude contrária é a reificação/coisificação: ver o outro como objeto, como coisa, negando sua liberdade, sua condição de sujeito".

Numa terceira etapa da reflexão, Luís Barzotto (2018, p. 84-84) aproxima o reconhecimento ao aspecto da reciprocidade (reconhecimento como reciprocidade), salientando que "reconhecer o irmão é afirmá-lo como igual a si mesmo e, portanto, [ter a consciência de que] o outro tem os mesmos direitos e os mesmos deveres"[que eu mesmo], numa relação, como ressai, incondicionalmente simétrica. Não haverá espaço, a contrario sensu, como por vezes se observa e ressalta o autor, para a parcialidade, onde se quer para si direitos e para os outros os deveres.

Ressignificando a liberdade e a igualdade, como antes sugerido por Amalia Amaya, apresenta Luís Fernando Barzotto, ao final do seu importante estudo, uma proposta conceitual de fraternidade: "a fraternidade é uma atitude complexa de reconhecimento do outro como irmão, na solidariedade com ele (o outro é membro da minha comunidade), no respeito (o outro é livre) e na reciprocidade (o outro é igual a mim)".

A fraternidade, assim compreendida, apresentar-se-á também como princípio, mas,

\footnotetext{
${ }^{4}$ Tratando da dimensão comunitária da fraternidade, acrescenta Amalia Amaya (2016, p. 30): "El reconocimiento mutuo de los miembros de una comunidad fraternal como iguales en virtud de la cualidad compartida implica también el reconocimiento recíproco de un cierto estatus normativo: lo que están unidos por una relación fraternal se reconocen como indivíduos que tienen los mismos derechos, obligaciones y responsabilidades derivados del rasgo compartido".

${ }^{5}$ Aduz a autora: "La relación fraternal es [...] un relación de ayuda mutua y cooperação voluntaria. El carácter altruista de los aspectos prácticos de la fraternidad no impide, sin embargo, que la fraternidad se pueda expresar en una serie de responsabilidades, obligaciones y expectativas" (2016, p. 31).
} 
particularmente, como ensina Antonio Maria Baggio (2008, p. 54), como princípio regulador do princípio da igualdade e do princípio da fraternidade. Conclui o autor: "se vivida fraternalmente, a liberdade não se torna arbítrio do mais forte, e a igualdade não degenera em igualitarismo opressor".

\section{Fraternidade como categoria jurídica: uma proposta para o momento em que vivemos}

Com lastro em tais reflexões, a propósito da relação liberdade-igualdade-fraternidade, é possível dizer que, com a consagração da fraternidade na Constituição Federal de 1988 agora já compreendida numa perspectiva jurídica - as clássicas dimensões liberal e social de direitos (construir uma sociedade livre/liberdade e construir uma sociedade justa/igualdade) passaram a se desenvolver devidamente adensadas, indissociável e reciprocamente, agora catalisadas (ou ressignificadas) pela fraternidade (MACHADO, 2017a, p. 139).

Retomando a discussão e tendo presente o alcance conceitual da fraternidade, com os elementos contemplados, consoante as lições de Amaya e Barzotto, tem-se que, do ponto de vista eminentemente jurídico, muito mais do que elencar situações que evidenciem direitos de fraternidade, o momento de emergência sanitária pede o tratamento do tema numa perspectiva de deveres, de responsabilidade social, comprometimento com a comunidade.

Não se olvide da Declaração Universal dos Direitos do Homem, ao estabelecer, no seu art. XXIX, item 1, que "todo ser humano tem deveres para com a comunidade, na qual o livre e pleno desenvolvimento de sua personalidade é possível”.

Deveres, que se apresentam associados, não à liberdade, nem à igualdade, mas à fraternidade, como aduz, conclusivamente, Clara Machado (2017, p. 174):

Com a fraternidade, a perspectiva dos deveres ganha nova dimensão já que a
construção de uma sociedade fraterna depende não só do Estado prestador e garantidor
de direitos, como também de indivíduos comprometidos com uma cidadania ativa e
inclusiva que reconheçam seus deveres tendo em vista o bem-estar social, admitindo-
se, inclusive, limitações ao exercício dos direitos fundamentais.

Vale a lembrança de que a limitação dos direitos fundamentais, a partir da imposição de deveres, dependerá sempre de lei, mesmo no aspecto da saúde. É sabido que a saúde, apresenta-se como direito de todos, consagrado constitucionalmente, mas dever do Estado, conforme a inequívoca dicção do art. 196, da Constituição Federal, "garantido mediante políticas sociais e econômicas que visem à redução do risco de doença e de outros agravos e ao acesso universal e igualitário às ações e serviços para sua promoção, proteção e recuperação".

Como destaca o Min. Néfi Cordeiro, em reflexivo artigo ("Pandemia e conflito, com 
esperança"), publicado em 04 de junho de 2002, no CONJUR, "a pandemia do Covid-19 surpreende pela gravidade da doença e, especialmente em nosso país, pela evolução dos conflitos - pessoais e institucionais".

De fato, como destaca o julgador do Superior Tribunal de Justiça, “entre tantos princípios constitucionais a serem neste momento relembrados para a melhoria da sociedade, talvez um único, uniformizador, baste: humanismo". A fórmula, como destaca, "é o homem perceber-se e aos demais como iguais em dignidade e opções de vida [...]”. Humanismo; humanismo necessário, que já é reconhecido, inclusive, como categoria constitucional (BRITTO, 2007) e como tal deve ser compreendido. Humanismo, fundamento do princípio da fraternidade.

\section{Conclusão}

Fraternidade, assimilada como princípio, valor, categoria, que tem na sua essência o "viver com os outros". Paradoxalmente a sociedade foi levada, em razão da pandemia, ao isolamento social e, como destaca nota da Pontifícia Academia para a Vida, expedida em 30 de março de 2020,

A pandemia do Covid-19 nos coloca numa situação de dificuldade sem precedentes,
dramática e global: a sua força de desestabilização do nosso projeto de vida cresce a
cada dia. Estamos vivendo um paradoxo que nunca teríamos imaginado: para
sobreviver à doença, devemos nos isolar uns dos outros, e vivendo assim, percebemos
que viver com os outros é essencial para a nossa vida.

A partir do reconhecimento das nossas vulnerabilidades, em todos os aspectos (física, cultural, econômica e política), acrescenta a Nota que em tempo de incertezas, além das medidas sanitárias em razão da pandemia urge que a humanidade assuma, também, a "responsabilidade na contribuição reflexiva sobre o significado dos valores do humanismo".

O Direito deverá dar o seu contributo na concretização do princípio constitucional da fraternidade, com a utilização de uma nova hermenêutica na compreensão e alcance de textos normativos infraconstitucionais, como vem ocorrendo na seara do direito penal e do processo penal (mitigação das hipóteses de cerceamento provisório de liberdade e até deferimento excepcional de prisões domiciliares em situações de cumprimento de pena), com a concessão, por vezes, de ordem, no julgamento de diversos habeas corpus coletivos (o que não se revela usual), mas também e particularmente na releitura de diversos institutos jurídicos por meio de uma visão mais humanista.

À guisa de conclusão, invoca-se a reflexão de Néfi Cordeiro (2020a), para com ele 
também afirmar: "Em tempos de pandemia, seja o isolamento social o único admitido e não o isolamento das emoções ou da compreensão do outro".

Muito provavelmente o mundo pós-pandemia estará mais pobre e sofrido. No entanto, deve-se ter sempre presente a esperança, assim como sublinhou o Min. Luís Roberto Barroso, no discurso de cerimônia de posse na Presidência, no dia 24 de maio de 2020.

[Que] a provação pela qual estamos passando seja tão breve quanto possível e que o
dia seguinte da crise encontre a humanidade e nosso país mais conscientes dos seus
problemas reais, mais solidários perante nossos irmãos e mais comprometidos com os
valores que fazem a grandeza das nações: justiça, igualdade de oportunidades para
todos e um sentimento verdadeiro de solidariedade e comunhão fraterna. Que a
distância que hoje nos separa das pessoas queridas ajude-nos a redescobrir o poder
revolucionário da afetividade e do bem-querer.

Nesse passo, e parafraseando o Papa Francisco, que a humanidade, doravante, deixese "contagiar pela esperança".

Para tanto, digno de destaque trecho de decisão monocrática do Min. Rogerio Schietti Cruz (BRASIL, 2020) quando, indeferindo liminarmente o processamento de Habeas Corpus coletivo que pleiteava o relaxamento de medidas de isolamento social, pronunciou-se propugnando que não nos faltasse:

"Uma leitura, uma vivência e um respeito ao que nos propusemos a fazer como povo,
que, na dicção do preâmbulo e dos primeiros artigos de nossa Constituição, se propõe
a formar uma sociedade fraterna [...], apoiada sobre princípios como da dignidade da
pessoa humana [...], com o objetivo de construir uma sociedade livre, justa e solidária
[...]".

A pandemia fez a humanidade compreender um incontestável fato: ninguém se salvará sozinho. E mais: "estar atento ao outro é importante para a sobrevivência de todos" (NICOSIA, 2020, p. 3). Proceder assim é assumir uma prática fraterna.

O Direito também poderá ser compreendido a partir do Princípio da Fraternidade. Mais do que faculdade, é mandamento constitucional.

\section{REFERÊNCIAS}

ABRAHÃO, Jorge. Um vírus democrático que evidencia a fragilidade da democracia. 01.04.2020. Disponível em: https://www.nossasaopaulo.org.br/2020/04/01/um-virusdemocratico-que-evidencia-a-fragilidade-da-democracia/. Acesso em: 30 jun. 2020.

AMAYA, Amalia. La relevancia de la fraternidad. In: LEROUX, Sergio Ortiz (coordinador). Las formas de la fraternidad. México: Ediciones Coyoacán, 2016. Disponível em: http://www.filosoficas.unam.mx/docs/36/files/Las\%20formas\%20de\%201a\%20fraternidad.pd f. Acesso em: 28 jun. 2020.

AMAYA, Amalia. La Relevancia de la Fraternidad. Disponível me: 
https://law.yale.edu/sites/default/files/area/center/kamel/sela17_amaya_cv_sp.pdf, Acesso em: 24 jun. 2020.

BAGGIO, Antonio Maria. O Princípio esquecido/1. Vargem Grande Paulista: Cidade Nova, 2008.

BARROS, Sérgio Resende de. Aulas. Noções sobre Gerações de Direitos. Disponível em: http://www.srbarros.com.br/pt/nocoes-sobre-geracoes-de-direitos.cont. Acesso em: 28 jun. 2010.

BARROS, Sérgio Resende de. Artigos. Três Gerações de Direitos. Disponível em: http://www.srbarros.com.br/pt/tres-geracoes-de-direitos.cont. Acesso em: 28 jun. 2020.

BARROSO, Luís Roberto. Discurso de Posse na Presidência do Tribunal Superior Eleitoral. 24 de maio de 2020. Disponível em:

https://www.migalhas.com.br/arquivos/2020/5/A973B4A4317DE3_discursobarroso.pdf. Acesso em: 30 jun. 2020.

BARZOTTO, Luís Fernando. Fraternidade: uma aproximação conceitual. In: MACHADO, Carlos Augusto Alcântara; JABORANDY, Clara Cardoso e BARZOTTO, Luciane Cardoso. Direito e Fraternidade: em busca de concretização. Aracaju: EDUNIT, 2018.

BAYLOS, Pe. Francisco Javier Sotil. Esquemas de filosofia zubiriana. Filosofia do Homem.(Apostilas), 2003. Disponível em:

http://www.zubiri.org/outlines_syllabi/antropologia03.htm. Acesso em: 20 jun. 2020.

BONAVIDES, Paulo. Curso de Direito Constitucional. 26. ed., São Paulo: Malheiros, 2011.

BOBBIO, Norberto. A Era dos Direitos. Rio de Janeiro: Elsevier, 2004.

BRASIL. Superior Tribunal de Justiça. HABEAS CORPUS No 580653 - PE (2020/01111685). Rel. Min. Rogerio Schietti Cruz. D. em 20.05.2020. Disponível em:

http://www.stj.jus.br/sites/portalp/SiteAssets/documentos/noticias/HC580653\%20PE.pdf. Acesso em: 30 jun. 2020.

BRITTO, Carlos Ayres. O Humanismo como categoria constitucional. Belo Horizonte: Fórum, 2017.

CORDEIRO, Néfi. A pandemia da Covid-19 e as tecnologias na persecução criminal. In: Revista Consultor Jurídico, 5 de junho de 2020a. Disponível em:

https://www.conjur.com.br/2020-jun-05/nefi-cordeiro-pandemia-tecnologias-persecucaocriminal. Acesso em: 20 jun. 2020.

CORDEIRO, Néfi. Pandemia e conflito, com esperança. In: Revista Consultor Jurídico. 04 de junho de 2020b. Disponível em: https://www.conjur.com.br/2020-jun-04/nefi-cordeiropandemia-conflito-esperanca. Acesso em: 30 jun. 2020.

FONSECA, Reynaldo Soares da. O Princípio Constitucional da Fraternidade - Seu resgate no Sistema de Justiça. Belo Horizonte: Editora D'PLÁCIDO, 2019. 
LIMA, Vinícius. ECOA. Coluna OPINIÃO. Contágio é demisponível em:

https://www.uol.com.br/ecoa/colunas/opiniao/2020/03/16/contagio-e-democratico-prevencaonao-como-ajudar-quem-vive-na-rua.htm. Acesso em: 30 jun. 2020.

LIMA, Mariana. Observatório do Terceiro Setor. Covid-10: O vírus pode até ser democrático, mas a Pandemia, não. 08.06.2020b. Disponível em:

https://observatorio3setor.org.br/noticias/covid-19-o-virus-pode-ate-ser-democratico-mas-apandemia-nao/. Acesso em: 30 jun. 2020.

MACHADO, Carlos Augusto Alcântara. A fraternidade como categoria jurídica Fundamentos e Alcance (Expressão do Constitucionalismo Fraternal). Curitiba: Appris, $2017 \mathrm{a}$.

MACHADO, Clara. O Princípio Jurídico da Fraternidade - Um instrumento para proteção de Direitos Fundamentais Transindividuais, Rio de Janeiro: Lumen Juris, 2017 b.

MORÁN, Jesús. Siano (un) corpo. In: Città Nuova, Anno XLIV-n.5/Maggio 2020.

NICOSIA, Aurora. Il punto. In: Città Nuova, Anno XLIV-n.5/Maggio 2020.

TOSI, Giuseppe. A internacionalização dos Direitos Humanos: o desafio para o século XXI. In: Anais do I Seminário Nacional - Democracia, Direitos Humanos e Desenvolvimento, Aracaju: Instituto Braços; Projeto Estados de Direitos, 2014.

SEDUFSM. Notícias. Não há vírus ‘democrático’ em sociedades desiguais, analisam professores. Disponível em:

https://www.sedufsm.org.br/index.php?secao=noticias\&id=5855. Acesso em: 30 jun. 2020.

VATICANO. Pontifícia Academia para a Vida. Nota. Pandemia e Fraternidade. 30.03.2020. Disponível em: https://www.vaticannews.va/pt/vaticano/news/2020-03/notapontificia-academia-vida-pandemia-fraternidade-universal.html. Acesso em: 30 jun. 2020. 